\title{
Positive effect of colors and art in patient rooms on patient recovery after total hip or knee arthroplasty
}

\section{A randomized controlled trial}

\author{
Sandra Eminovic - Gabor Vincze (D) - Andrea Fink - Stefan F. Fischerauer - Patrick Sadoghi - Andreas Leithner • \\ Lars-Peter Kamolz · Karlheinz Tscheliessnigg • Gerwin A. Bernhardt
}

Received: 2 June 2021 / Accepted: 30 July 2021 / Published online: 7 September 2021

(C) The Author(s) 2021

\begin{abstract}
Summary
Background Environmental stimuli and well-being are considered to be significant factors in patients' rehabilitation. The aim of this study was to describe the effect of colors and art in hospital rooms on patients' recovery after total hip or knee arthroplasty.

Methods We performed a prospective randomized, controlled study including 80 patients. The intervention group was randomized to colored patient rooms while the control group received medical care in conventional patient rooms. Data were collected preoperatively and postoperatively ( 3 and 6 days after operation). We measured mood, anxiety and depression, quality of life (QOL) and pain.

Results Significantly better QOL summary scores were measured in the intervention group (6 days postoperative) compared to the control group (physical component summary score $37.1 \pm 5.0$ vs. $34.1 \pm 6.7$; $p=0.029$ and mental component summary score $51.6 \pm 6.6$ vs. $47.2 \pm 8.4 ; p=0.015$ ). Postoperatively, we found decreased total mood scores in both groups showing better results for the intervention group without significant differences ( $p=0.353 ; p=0.711$ ).
\end{abstract}

\footnotetext{
S. Eminovic, MSc · G. Vincze, MD, MSc $(\bowtie) \cdot A$. Fink, MSc • S. F. Fischerauer, MD, PhD · P. Sadoghi, MD, PhD, MBA · A. Leithner, MD · G. A. Bernhardt, MD, MBA Department of Orthopedics and Traumatology, Medical University of Graz, Auenbruggerplatz 5, 8036 Graz, Austria gabor.vincze@medunigraz.at
}

L.-P. Kamolz, MD

Division of Plastic, Aesthetic and Reconstructive Surgery, Medical University of Graz, Auenbruggerplatz 29, 8036 Graz, Austria

K. Tscheliessnigg, MD

Styrian Hospitals Limited Liability Company,

Stiftingtalstraße 4-6, $8010 \mathrm{Graz}$, Austria
Conclusion The use of colors in hospital rooms is an effective intervention to improve well-being and to enhance faster rehabilitation. We could demonstrate a positive effect of colors on patients' postoperative QOL.

Keywords Quality of life · Effect · Colors · Art · Arthroplasty

\section{Introduction}

Osteoarthritis is one of the most common joint disorders in adults. Due to the demographic change, an increasing number of older people with joint problems can be expected. Affected persons suffer from chronic pain, limited mobility and decreased quality of life (QOL) [1, 2]. The most affected joints are hip and knee. In advanced osteoarthritis total hip or knee arthroplasty is commonly performed, followed by postoperative rehabilitation, to improve the physical function [3]. So far research in total joint replacement has focused on clinical outcomes such as postoperative complications or revisions $[4,5]$.

Although hospitalization represents a stressful event, the well-being of patients during hospital stay has not been the focus of research to this point. Some studies demonstrated the well-being as a significant factor in patients' rehabilitation [6-9] and so clinical environment seems to have a significant negative impact on anxiety, stress response, sleep [8-12] and pain tolerance [13]. Frequent interruptions, noise or bright light were described as environmental issues affecting psychological components [14].

The environmental stimuli were found to be determining factors for patients' behavior [15, 16] and mood [17, 18]. Publications focused on the effects of environment (e.g., on mood or anxiety) in general; however, evidence regarding the impact of colors on 


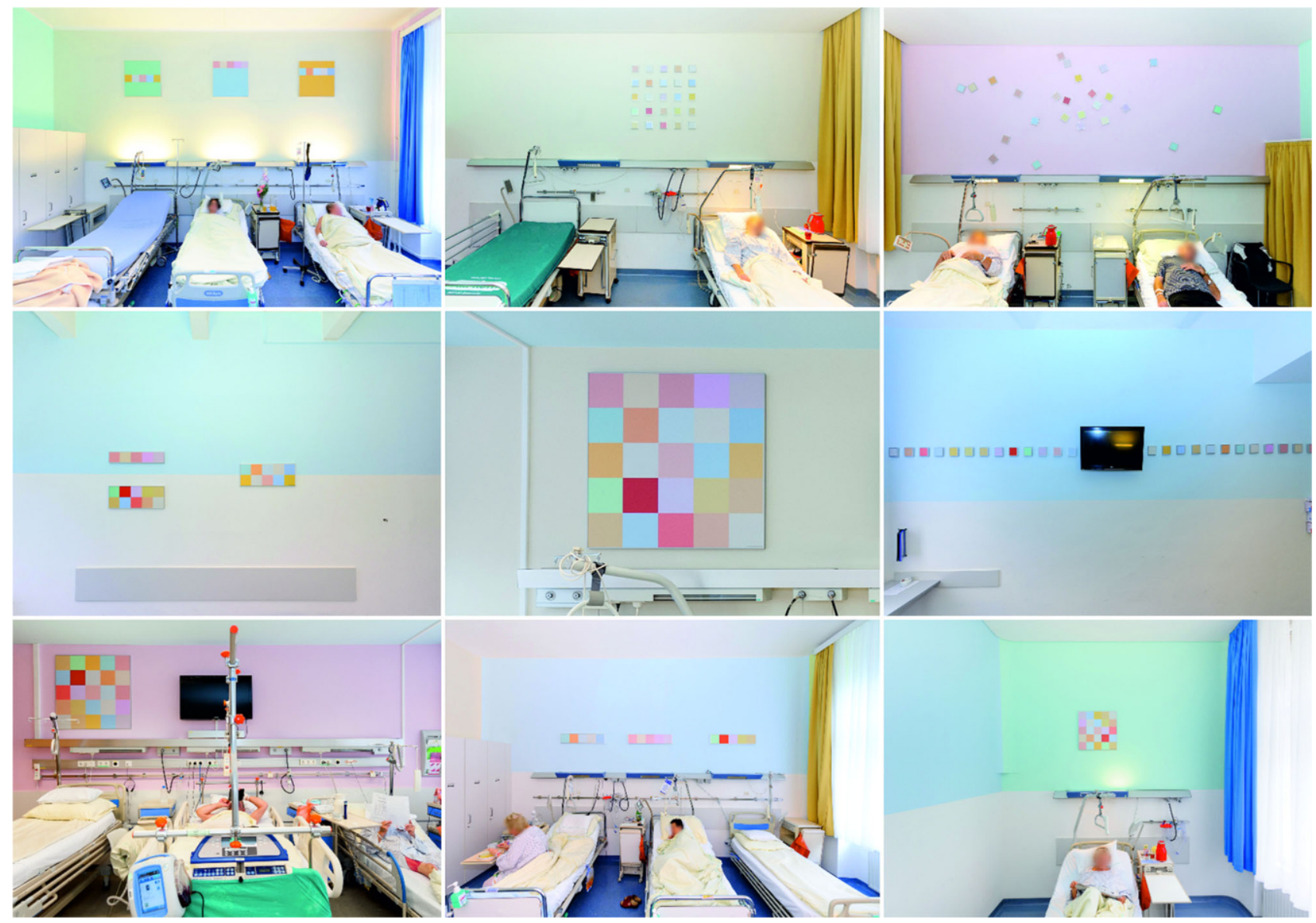

Fig. 1 Examples of patients rooms in the intervention group

patients' recovery is rare [6]. The aim of this study was to describe the effect of colors in patient rooms on (1) mood, (2) anxiety and depression (3) QOL and (4) pain in patients undergoing total arthroplasty. Our hypothesis was that patients receiving medical care in conventional patient rooms would have inferior scores in outcome parameters.

\section{Material and methods}

We performed a prospective randomized, controlled study including 80 patients. The participants were recruited at a department of orthopedic and trauma surgery at a university hospital. We included patients aged 50 years or older who underwent elective primary total hip (THA) or total knee arthroplasty (TKA). We selected patients planned for elective THA $(n=43)$ or TKA ( $n=37$ ) because of a comparable length of stay at our department. Intensive care patients were excluded.

The intervention group received usual medical care in colored patient rooms. The control group was randomly selected to a conventional patient room with white-colored walls receiving the same medical care. The colors used in the intervention group rooms were selected according to the ideas of an art theorist who developed six color codes for the intervention rooms assuming that light colors have calming effects on mood (Fig. 1). These color codes were additionally framed as pictures (art) and were placed in these rooms (Fig. 1). Each patient was placed in multiperson rooms. Every room included four beds and two windows. Included patients shared the room with three other orthopedic patients over the length of stay. Because the view from the window has an effect on patients' responses [19], we used rooms with the same outlook in each group.

Patients were evaluated preoperatively (baseline), 3 days after operation (time point 1) and 6 days after operation (time point 2). At each time point we assessed mood, anxiety and depression, quality of life and pain.

Patients' chronic medical conditions were assessed using the Charlson comorbidity index (CCI) [20] at admission. The mini-mental state examination (MMSE) [21] measured patients' cognitive state on admission day. Mood was evaluated using profile of mood states brief form (POMS Brief) [22]. The German version of the questionnaire consisted of the four scales: (1) anger, (2) fatigue, (3) vigor and (4) depression. The effect of colours on the anxiety and depression level was evaluated using the hospital anxiety and 
Table 1 Demographic data and patient characteristics

\begin{tabular}{|l|l|l|l|l|}
\hline & $\begin{array}{l}\text { Control group } \\
n=40\end{array}$ & $\begin{array}{l}\text { Intervention } \\
\text { group } \\
n=40\end{array}$ & $\begin{array}{l}p \text {-value } \\
\text { Gender (female) }\end{array}$ & $\begin{array}{l}\text { Overall } \\
n=80\end{array}$ \\
\hline Age (years) & $66.8( \pm 8.7)$ & $15(25)$ & 0.260 & $45(35)$ \\
\hline CCl & $1.0(0-5)$ & $1.0(0-4)$ & 0.727 & $1.0(0-5)$ \\
\hline MMSE & $28(17-30)$ & $28.5(22-30)$ & 0.170 & $28.0(17-30)$ \\
\hline $\begin{array}{l}\text { Length of hos- } \\
\text { pital stay (days) }\end{array}$ & $8.3( \pm 2.1)$ & $8.2( \pm 1.7)$ & 0.864 & $8.3( \pm 1.9)$ \\
\hline \begin{tabular}{l} 
Data presented as median and range \\
\hline
\end{tabular} & & & & \\
\hline
\end{tabular}

depression scale (HADS) [23]. Patients answered how they had been feeling over the last 3 days. The evaluation was conducted on admission (as baseline) and 3 and 6 days after the operation. The HADS is a 14item questionnaire measuring the anxiety and depression level, 7 items measured depression and the other 7 items measured anxiety. Total score ranges from 0 to 21 and each item is rated on a 4-point scale (0-3 points). For QOL assessment, we used the short form health survey (SF-12) questionnaire [24]. The SF-12 as a shorter version of the SF-36 using 12 questions to measure functional health and patient's well-being. Results are expressed as summary scores, (1) physical component summary (PCS) and (2) mental component summary (MCS). The PCS and MCS scores have a range of 0 to 100 . Higher numbers indicate better results. The degree to which pain is related to the environment was estimated by the brief pain inventory (BPI) [25]. We used the validated German version including the key components sensory pain and pain-related impairment.

Questionnaires were handed out to the patients. They received help from a study nurse if necessary in filling out, who was not involved in the study and therefore also blinded to the intervention so that she could not have any impact on the answers of the patients. At the department three medical doctors who performed the study were informed about the intervention; however, neither the surgeons, nurses nor physiotherapists were involved in the study.

For statistical analysis, continuous variables are presented as mean and standard deviation or median and minimum, maximum, and categorical variables are presented as frequencies and percentages. Group comparisons were performed by using $T$-test or Mann-Whitney $U$-test, as appropriate. The statistical analysis was performed using the statistical software SPSS, Version 22 (IBM SPSS Statistics for Windows, IBM Corp, Armonk, NY, USA). $P$-values $<0.05$ were considered significant. The study was approved by the local institutional review board (number: 27-138 ex 14/15). The work has been reported in line with consolidated standards of reporting trials (CONSORT) guidelines.
Table 2 Preoperative and postoperative results of the SF12 and POMS

\begin{tabular}{|c|c|c|c|}
\hline Outcome & $\begin{array}{l}\text { Control group } \\
n=40\end{array}$ & $\begin{array}{l}\text { Intervention group } \\
n=40\end{array}$ & $p$-value \\
\hline \multicolumn{4}{|c|}{ Preoperative } \\
\hline \multicolumn{4}{|l|}{$S F-12$} \\
\hline $\mathrm{PCS}^{\mathrm{a}}$ & $31.3( \pm 6.3)$ & $31.4( \pm 6.5)$ & 0.958 \\
\hline MCS $^{a}$ & $45.4( \pm 9.3)$ & $47.5( \pm 8.7)$ & 0.328 \\
\hline \multicolumn{4}{|l|}{ POMS } \\
\hline Total & $85.5(37-164)$ & $76.0(35-180)$ & 0.528 \\
\hline Anger & $3.0(0-19)$ & $2.0(0-21)$ & 0.858 \\
\hline Fatigue & $12.0(0-32)$ & $12.0(0-31)$ & 0.768 \\
\hline Vigor $^{a}$ & $16.0( \pm 7.7)$ & $15.9( \pm 5.7)$ & 0.149 \\
\hline Depression & $6.0(0-52)$ & $8.0(0-36)$ & 0.724 \\
\hline \multicolumn{4}{|c|}{ Time point 1} \\
\hline \multicolumn{4}{|l|}{$S F-12$} \\
\hline $\mathrm{PCS}^{\mathrm{a}}$ & $32.2( \pm 5.5)$ & $33.7( \pm 6.5)$ & 0.246 \\
\hline MCS $^{a}$ & $46.1( \pm 9.8)$ & $49.5( \pm 8.4)$ & 0.094 \\
\hline \multicolumn{4}{|l|}{ POMS } \\
\hline Total & $34.0(10-103)$ & $30.0(5-78)$ & 0.353 \\
\hline Anger & $2.5(0-18)$ & $1.0(0-16)$ & 0.328 \\
\hline Fatigue & $8.0(0-26)$ & $9.5(0-24)$ & 0.619 \\
\hline Vigor $^{\mathrm{a}}$ & $15.5( \pm 6.8)$ & $15.9( \pm 7.0)$ & 0.846 \\
\hline Depression & $6.0(0-56)$ & $5.0(0-29)$ & 0.521 \\
\hline \multicolumn{4}{|c|}{ Time point 2} \\
\hline \multicolumn{4}{|l|}{ SF-12 } \\
\hline $\mathrm{PCS}^{\mathrm{a}}$ & $34.1( \pm 6.7)$ & $37.1( \pm 5.0)$ & 0.029 \\
\hline $\mathrm{MCS}^{\mathrm{a}}$ & $47.2( \pm 8.4)$ & $51.6( \pm 6.6)$ & 0.015 \\
\hline \multicolumn{4}{|l|}{ POMS } \\
\hline Total & $33.0(11-107)$ & 31.5 (14-91) & 0.711 \\
\hline Anger & $3.0(0-15)$ & $2.0(0-15)$ & 0.330 \\
\hline Fatigue & $7.5(0-29)$ & $8.0(1-27)$ & 0.412 \\
\hline Vigor $^{\mathrm{a}}$ & $15.2( \pm 6.4)$ & $16.4( \pm 7.0)$ & 0.435 \\
\hline Depression & $5.0(0-54)$ & $4.5(0-43)$ & 0.794 \\
\hline
\end{tabular}

\section{Results}

The majority of patients were male $(n=45,56.3 \%)$ and the mean age was $67.3 \pm 9.4$ years. The median CCI was 1.0 (range 0-5) and the median MMSE was 28.0 (range 17-30). Postoperatively, no complications were observed in both groups. The length of hospital stay did not differ between the groups $(p=0.864)$. Demographic data and patient characteristics are presented in Table 1.

\section{Quality of life}

The PCS and MCS scores of the SF-12 increased in both groups continuously after operation. At time point 2 after the operation significantly higher PCS $(p=0.029)$ and MCS scores $(p=0.015)$ were measured in the intervention group. Results of the SF-12 are demonstrated in Table 2. 


\section{Mood}

Low values of total POMS score were observed in intervention group on time point 1 (median $=30$ ) and time point 2 (median $=31.5$ ) without significant differences ( $p=0.353 ; p=0.711)$. Results of the POMS score are presented in Table 2.

\section{Anxiety and depression}

The mean anxiety and depression score decreased in both groups at time point 1 and 2 after operation without significant difference. Results of the HADS score are demonstrated in Table 3.

\section{Pain}

The mean sensory pain score of patients remained high in both groups after operation. No significant differences were found in sensory pain at time point 1 $(p=0.649)$ and time point $2(p=0.137)$ after the operation in both groups. Pain-related impairment scores decreased on time point 1 after operation $(p=0.162)$ in the intervention $(23.6 \pm 9.8)$ and control groups $(26.9 \pm 9.8)$. Overall results of the BPI questionnaire are described in Table 3.

Table 3 Preoperative and postoperative results of the HADS score and brief pain inventory

\begin{tabular}{|c|c|c|c|}
\hline Outcome & $\begin{array}{l}\text { Control group } \\
n=40\end{array}$ & $\begin{array}{l}\text { Intervention group } \\
n=40\end{array}$ & $\begin{array}{l}p- \\
\text { value }\end{array}$ \\
\hline \multicolumn{4}{|c|}{ Preoperative } \\
\hline \multicolumn{4}{|l|}{ HADS } \\
\hline Anxiety & $3.0(0-14)$ & $2.0(0-12)$ & 0.204 \\
\hline Depression & $6.0(0-14)$ & $3.0(0-15)$ & 0.067 \\
\hline \multicolumn{4}{|c|}{ Brief pain inventory } \\
\hline Sensory pain ${ }^{\mathrm{a}}$ & $16.8( \pm 6.6)$ & $16.5( \pm 5.1)$ & 0.063 \\
\hline $\begin{array}{l}\text { Pain-related } \\
\text { impairment }^{\mathrm{a}}\end{array}$ & $29.7( \pm 11.1)$ & $25.9( \pm 8.4)$ & 0.300 \\
\hline \multicolumn{4}{|l|}{ Time point 1} \\
\hline \multicolumn{4}{|l|}{ HADS } \\
\hline Anxiety & $3.0(0-12)$ & $1.0(0-9)$ & 0.209 \\
\hline Depression $^{\mathrm{a}}$ & $4.3( \pm 2.9)$ & $3.8( \pm 3.9)$ & 0.769 \\
\hline \multicolumn{4}{|c|}{ Brief pain inventory } \\
\hline Sensory pain ${ }^{\mathrm{a}}$ & $17.4( \pm 6.2)$ & $16.8( \pm 6.3)$ & 0.649 \\
\hline $\begin{array}{l}\text { Pain-related } \\
\text { impairment }^{\text {a }}\end{array}$ & $26.9( \pm 9.8)$ & $23.6( \pm 9.8)$ & 0.162 \\
\hline \multicolumn{4}{|l|}{ Time point 2} \\
\hline \multicolumn{4}{|l|}{ HADS } \\
\hline Anxiety & $3.0(0-12)$ & $1.0(0-11)$ & 0.235 \\
\hline Depression $^{\mathrm{a}}$ & $4.0( \pm 3.5)$ & $3.2( \pm 3.4)$ & 0.462 \\
\hline \multicolumn{4}{|c|}{ Brief pain inventory } \\
\hline Sensory pain ${ }^{\mathrm{a}}$ & $16.7( \pm 5.2)$ & $14.5( \pm 4.3)$ & 0.137 \\
\hline $\begin{array}{l}\text { Pain-related } \\
\text { impairment }^{\mathrm{a}}\end{array}$ & $25.7( \pm 6.8)$ & $22.8( \pm 10.0)$ & 0.119 \\
\hline
\end{tabular}

\section{Discussion}

To the best of our knowledge this is the first prospective study evaluating the effects of colors and art in patient rooms on the well-being of surgical patients. The aim of this study was to describe the effect of colors and art in patient rooms on patients' well-being including (1) mood, (2) anxiety and depression (3) quality of life and (4) pain. The hypothesis of the study was that patients receiving medical care in conventional patient rooms would have inferior outcome scores postoperatively. Furthermore, we decided to make measurements on repeated time points to indicate the progress of each outcome during hospitalization. Patients were evaluated preoperatively (baseline), 3 days after operation (time point 1) and 6 days after operation (time point 2). Compared to time point 1 and 2 our results showed worse mood and anxiety scores on admission day in both groups. We assume that this result reflects preoperative stress due to the planned surgical intervention. Previous research showing similar levels of preoperative anxiety [26, 27] confirm our results. Postoperatively, we did not find any significant differences in mood scores or the subscales between groups and the remaining scores (e.g. HADS or BPI questionnaire) did not show significant differences after the operation between the groups except the SF-12 results. We measured higher PCS (37.1 $\pm 5 ; p=0.029)$ and MCS scores $(51.6 \pm 6.6 ; p=0.015)$ on time point 2 in the intervention group. Thus, the results indicate that colored patient rooms have an influence on the postoperative well-being of patients. Comparable results were not available as there is a lack of studies evaluating the same outcomes.

A lack of this study was that we did not evaluate patients' perceptions of physical conditions in the healthcare setting. Therefore, we could not identify the environmental sources of satisfaction or the overall satisfaction with the hospital experience. When patients' perceptions are taken into account to predict the satisfaction, they often appear as a significant contributor [28]. Moreover, high-quality research evaluating the impact of environment on patients' well-being is very challenging because of several influencing factors in hospitals such as light or sound [12]. We used recommended and validated scores [22-25] assessing the described outcomes. It could also have a positive psychological side effect that patient's rooms were more individualized than normally and patients feel themselves more comfortable and personalized in that environment. Only German versions of scores were applied to interview study patients. We included scores with high results in validity, reliability, sensitivity and specificity [22-25].

Past research analyzed the stimuli of patients to various colors but without conducting the study in a real-life setting $[7,29,30]$. While some other investigations focused on the effects of healthcare environment, in general evidence regarding the impact of col- 
ors on patients' postoperative rehabilitation is lacking $[6,18]$. Based on these facts we designed a study in a real-life setting to describe the well-being of surgical patients. We tried to control several influencing factors, e.g. the view from the window or length of stay. Patients were assigned to fully occupied rooms. Our findings offer useful aspects for planning future hospital redevelopments. Based on our results a larger cohort has to focus on effects of healthcare environment including the impact of colors on well-being and rehabilitation. Larger effects were observed at the later time point, following the assumption that more significant results could be demonstrated for prolonged hospitalization time. Studies should therefore focus on patients over longer hospitalization periods, such as in rehabilitation hospitals. Research should examine the environmental effects especially on surgical patients because the preoperative emotional status of patients alters the endocrine and metabolic function [31].

\section{Conclusion}

We could show a significant positive effect of colors on patients' postoperative QOL. The use of colors in hospital rooms is an effective and low-cost intervention to improve well-being and possibly to enhance a faster rehabilitation. Further studies are needed to confirm our results in a larger cohort. Investigations have to focus on the impact of healthcare environment including other influencing aspects such as light, sound, temperature or patients' perceptions of the physical environment as previously described [28, 32-35].

Acknowledgements Special thanks go to independent art theorist, Richard Kriesche, who precisely developed the color codes for intervention rooms. Thanks go to graduated nurses, Christoph Kumpitsch and Katharina Grof, who assisted the project.

Author Contribution S. Eminovic, G. Vincze, A. Fink, S.F. Fischerauer, P. Sadoghi, A. Leithner, L.-P. Kamolz, K. Tscheliessnigg, G.A. Bernhardt: study design, data collection, writing.

Funding Open access funding provided by Medical University of Graz.

\section{Declarations}

Conflict of interest S. Eminovic, G. Vincze, A. Fink, S.F. Fischerauer, P. Sadoghi, A. Leithner, L.-P. Kamolz, K. Tscheliessnigg and G.A. Bernhardt declare that they have no competing interests.

Ethical standards All procedures performed in studies involving human participants or on human tissue were in accordance with the ethical standards of the institutional and/or national research committee and with the 1975 Helsinki declaration and its later amendments or comparable ethical standards. The study was approved by the local Institutional Review Board (number: 27-138 ex 14/15). Provenance and peer review not commissioned, externally peer reviewed. Informed consent was obtained from all patients for being included in the study.

Open Access This article is licensed under a Creative Commons Attribution 4.0 International License, which permits use, sharing, adaptation, distribution and reproduction in any medium or format, as long as you give appropriate credit to the original author(s) and the source, provide a link to the Creative Commons licence, and indicate if changes were made. The images or other third party material in this article are included in the article's Creative Commons licence, unless indicated otherwise in a credit line to the material. If material is not included in the article's Creative Commons licence and your intended use is not permitted by statutory regulation or exceeds the permitted use, you will need to obtain permission directly from the copyright holder. To view a copy of this licence, visit http://creativecommons.org/licenses/by/4.0/.

\section{References}

1. Dekker J, van Dijk GM, VeenhofC. Riskfactors for functional decline in osteoarthritis of the hip or knee. Curr Opin Rheumatol. 2009;21:520-4.

2. Van Dijk GM, Dekker J, VeenhofC, van den Ende CH. Course of functional status and pain in osteoarthritis of the hip or knee: a systematic review of the literature. Arthritis Rheum. 2006;55:779-85.

3. St Clair SF, Higuera C, Krebs V, Tadross NA, Dumpe J, Barsoum WK. Hip and knee arthroplasty in the geriatric population. Clin Geriatr Med. 2006;22:515-33.

4. Hwang SK. Experience of complications of hip arthroplasty. Hip Pelvis. 2014;26:207-13.

5. Belmont PJJ, Goodman GP, Waterman BR, Bader JO, SchoenfeldAJ.Thirty-daypostoperative complications and mortality following total knee arthroplasty: incidence and risk factors among a national sample of 15,321 patients. JBone Joint SurgAm. 2014;96:20-6.

6. Ampt A, Harris P, Maxwell M. The health impacts of the design of hospital facilities on patient recovery and wellbeing, and staff wellbeing: a review of the literature. 2008. https://www.swslhd.health.nsw.gov.au/ populationhealth/PH_environments/pdf/Rpt_Liverpool_ Redev_Design_Impact.pdf. Accessed 30 May 2018, University of New South Wales: Sydney.

7. Salonen H, Morawska L. Physical characteristics of the indoor environment that affect health and wellbeing in healthcarefacilities: a review. Intell Build Int. 2013;5:3-25.

8. Lorenz SG. The potential of the patient room to promote healing and well-being in patients and nurses: an integrative review of the research. Holist Nurs Pract. 2007;21:263-77.

9. Van de Glind I, de Roode S, Goossensen A. Do patients in hospitals benefit from single rooms? A literature review. Health Policy. 2008;84:153-61.

10. Saffarinia M, Tavakkoli S, Alipor A. Effects of environmental design inspired by nature on psychological and physiological responses of clients in medical spaces. Int J Environ Res. 2012;6:689-94.

11. Ulrich R, Quan X. The role of the physical environment in the hospital of the 21st century: a once-in-a-lifetime opportunity. 2004. https://www.healthdesign.org/sites/ default/files/Role\%20Physical\%20Environ\%20in\%20the \%2021st\%20Century\%20Hospital_0.pdf. Accessed 30 May 2018.

12. Devlin AS, ArneillAB. Health care environments and patient outcomes: a review of the literature. Environ Behav. 2003;35:665-94. 
13. Jastremski CA. ICU bedside environment: a nursing perspective. Crit Care Clin. 2000;16:723-34.

14. BaHammam A. Sleep in acute care units. Sleep Breath. 2006;10:6-15.

15. Gifford R. Light, decor, arousal, comfort, and communication. JEnviron Psychol. 1988;8:177-89.

16. Mattila AS, Wirtz J. Congruency of scent and music as a driver of in-store evaluations and behaviour. J Retail. 2001;77:273-89.

17. Knez I. Effects of colour of light on nonvisual psychological processes. JEnviron Psychol. 2001;21:201-8.

18. Leather P, Beale D, Santos A, Watts J, Lee L. Outcomes of environmental appraisal of different hospital waiting areas. Environ Behav. 2003;35:842-69.

19. Ulrich RS. View through a window may influence recovery from surgery. Science. 1984;224:420-1.

20. Charlson ME, Pompei P, Ales KL, MacKenzie CR. A new method of classifying prognostic comorbidity in longitudinal studies: development and validation. J Chronic Dis. 1987;40:373-83.

21. Folstein MF, Folstein SE, McHugh PR. Mini-mental state. A practical method for grading the cognitive state of patients for the clinician. J Psychiatr Res. 1975;12:189-98.

22. Albani C, Blaser G, Geyer M, Schmutzer G, Brähler E, Bailer $\mathrm{H}$, et al. The German short version of "Profile of Mood States" (POMS): psychometric evaluation in a representative sample. Psychother Psychosom Med Psychol. 2005;55:324-30.

23. Bjelland I, Dahl AA, Haug TT, Neckelmann D. The validity of the Hospital Anxiety and Depression Scale. An updated literature review. J Psychosom Res. 2002;52:69-77.

24. Luo X, George ML, Kakouras I, Edwards CL, Pietrobon R, Richardson W, et al. Reliability, validity, and responsiveness of the short form 12-item survey (SF-12) in patients with back pain. Spine. 2003;28:1739-45.

25. Radbruch L, Loick G, Kiencke P, Lindena G, Sabatowski R, Grond S, et al. Validation of the German version of the Brief Pain Inventory. J Pain Symptom Manage. 1999;18:180-7.
26. Jawaid M, Mushtaq A, Mukhtar S, Khan Z. Preoperative anxiety before elective surgery. Neurosciences (Riyadh). 2007;12:145-8.

27. Jafar MF, KhanFA. Frequency of preoperative anxiety in Pakistani surgical patients. JPak Med Assoc. 2009;59:359-63.

28. Andrade CC, Lima ML, Devlin AS, Hernandez B. Is it the place or the people? Disentangling the effects of Hospitals' physical and social environments on well-being. Environ Behav. 2016;48:299-323.

29. Dijkstra K, Pieterse ME, Pruyn ATH. Individual differences in reactions towards color in simulated healthcare environments: the role of stimulus screening ability. J Environ Psychol. 2008;28:268-77.

30. Gray WA, Kesten KS, Hurst S, Day TD, Anderko L. Using clinical simulation centers to test design interventions: a pilot study of lighting and color modifications. HERD. 2012;5:46-65.

31. Tolksdorf W, Andrianopolos I, Schmollinger U, Ewen T, Berlin J. The relationship between pre-operative emotional states and stress-linked parameters in surgical patients (author's transl). Anasth Intensivther Notfallmed. 1982;17:21-8.

32. Tofle RB, Schwartz B, Yoon SY, Max-Royale A. Color in healthcare environments-a research report. Coalition for Health Environments Research (CHER). 2004. https:// www.healthdesign.org/sites/default/files/color_in_hc_ environ.pdf. Accessed 30 May 2018.

33. Anthes E. The office experiment. Can science build the perfect workspace? Nature. 2016;537:294-6.

34. Sloan DA, Arneill AB. Health care environments and patient outcomes: a review of the literature. Environ Behav. 2003;35:665-94.

35. Huisman ERCM, Morales E, van Hoof J, Kort HSM. Healing environment: a review of the impact of physical environmental factors on users. Build Environ. 2012;58:70-80.

Publisher's Note Springer Nature remains neutral with regard to jurisdictional claims in published maps and institutional affiliations. 